Article title: The Nexus of the Critical Trio: Access, Equity and Quality in Distance Learning

Authors: Itumeleng Setlhodi[1]

Affiliations: University of South Africa[1]

Orcid ids: 0000-0003-2644-9570[1]

Contact e-mail: setlhii@unisa.ac.za

License information: This work has been published open access under Creative Commons Attribution License http://creativecommons.org/licenses/by/4.0/, which permits unrestricted use, distribution, and reproduction in any medium, provided the original work is properly cited. Conditions, terms of use and publishing policy can be found at https://www.scienceopen.com/.

Preprint statement: This article is a preprint and has not been peer-reviewed, under consideration and submitted to UnisaRxiv for open peer review.

DOI: 10.25159/UnisaRxiv/000020.v1

Preprint first posted online: 21 July 2021

Keywords: access, equity, quality, emergency remote teaching, distance learning, social justice 


\title{
The Nexus of the Critical Trio: Access, Equity and Quality in Distance Learning
}

\author{
Itumeleng I. Setlhodi \\ https://orcid.org/0000-0003-2644-9570 \\ University of South Africa \\ setlhii@unisa.ac.za
}

\section{Abstract}

Emergency remote teaching due to the Covid-19 pandemic has fast-tracked the need for transformation of distance learning, amplified issues of access and equity, and exposed the necessity to assure and ensure quality distance learning. This study applied a qualitative literature and material review by using the MAXQDA-analysis method to identify whether the current measures (following Covid-19 protocol) are accessible to all students at the right time and establishing links regarding access equity and quality. The results revealed that online distance education is a strategy to be enhanced towards ensuring credible distance learning. The results show the intersection and fit of access, equity, and quality in distance learning as perpetual social justice issues. Online education and what is required to make it accessible, related online learning material that is accessible for all, and needy students' support should therefore be prioritised.

Keywords: access, distance learning, equity, emergency remote teaching, quality, social justice

\section{Introduction}

There is no doubt that the Covid-19 pandemic has influenced the way in which students access teaching and learning modalities at a distance and learning in a climate of poor economic growth, which has an impact on access, equity issues, and the quality of education. Bates (2020) attests that Covid-19 exposed inequalities in the current system globally and the need for accessible low-cost internet access for quality learning. These effects need to be considered in line with a growing recognition of the increased lack of service due to the economic downturn, which lead to affordance issues (thereby raising access problems) in the e-learning space (open distance e-learning (ODeL)). The pandemic has accelerated long-term strategies of most educational institutions towards digital transformation of education to align with the demands of emergency remote teaching (ERT). This meant leaders of educational institutions had to redefine education provisioning towards meeting the challenges posed by the pandemic, which thrust equity and access matters to the fore (The World Bank 2020). This therefore led to the burden of recalibrating education delivery, changing assessment modalities, and highlighting the challenges of quality. Again, this also brought about the problem of 
access, inadvertently bringing equity problems back into the mainstream struggles, 27 years into democracy in South Africa.

The added pressure brought about by the loss of income due to the consequences of the Covid-19 lockdown led to a greater need to access education online and at a distance (LeGrange 2020). The struggles of equity and access due to the extent of the economic divide are sufficiently documented (Council on Higher Education 2015; Mncube and Madikizela-Madiya 2013; Ntombela and Setlhodi 2021). Even though measures were devised to enable students to observe social distancing by learning fully online, to comply with the pandemic protocol, some still struggle because of the inequalities that pervade South Africa (Sokhulu 2020), particularly those from impoverished and rural areas. There is currently sparse research on the impact of online learning platforms over the course of the Covid-19 pandemic (Mhlanga and Moloi 2020). This brings to sharp focus the nexus between equity and access and the way in which they have an impact on quality in education. The challenge for institutions of learning is to create a learning context that enable equal access to learning, and to maintain the quality of tuition and learning and the assessment procedures to be followed. Lucander and Christersson (2020) declare that quality assurance promotion is important in ensuring credibility and competence while safeguarding that there is equitable access to education. The need is therefore to reconsider the critical trio, quality, access and equity, while taking care of the needs of students from diverse backgrounds.

The effects of growing socio-economic disparities disadvantage those whose learning is disrupted because they lack cellphone data or other resources to connect when the need arise. Sokhulu (2020) found that some students' learning was interrupted and curtailed because of the inability to gain access to online platforms owing to cellphone data costs or other financial constraints. Dichaba and Setlhodi (2017) opine that affordance problems disadvantage students from deprived backgrounds, further exposing inequalities lingering from the past dispensation and the worsening issues of access and equity temperament in South Africa. Cloete (2011) describes these disparities, unequal and divided heritage, which violate the constitutional values of equity, access, and ubuntu and which raise social justice problems. The critical questions therefore are: To what extent are current measures (following Covid-19 protocol) accessible to all students at the right time? What is the link between equity and access in relation to quality?

The study embarked on a twofold exploration: first, to identify whether the current measures put in place are accessible to all students at the right time. Second, to establish the link regarding equity and access in relation to quality. The overarching literature is delineated together with the theoretical framework underpinning the study. Then the methodology, findings, discussions and recommendations are presented. 


\section{Conceptual Framework}

An illustration of the way in which measures following the pandemic are equally accessible or not, and the need to uphold quality require understanding of the concepts as they relate to the constitutional values. This section defines these concepts to map their meaningful conception and efficient utilisation in this study (Adom, Hussein, and Agyem 2018) by exploring large amounts of literature and other material towards building a conceptual framework (Casasempere-Satorres and Vercher-Ferrándiz 2021).

\section{The Significance of Access and Equity while Pursuing Quality: A Framework}

The Covid-19 pandemic is one challenge afflicting humanity the world over generally and South Africa specifically. Education institutions transitioned to ERT to observe the social distancing demanded by the pandemic protocol and to save the academic year (Madiope and Mendy 2021; Shuma 2020), leaving those who lack resources struggling to access online tuition and staying on an unequal learning turf (Ntombela and Setlhodi, 2018). Higher education has to be equally accessible and is imperative in bridging the equity gap, particularly in South Africa (Letseka, Letseka, and Pitsoe 2018, 122), while promoting the value of quality provisioning. Figure 1 illustrates the connection of achieving equity through accessible distance education, and ensuring quality towards responding adequately to the constitutional values.

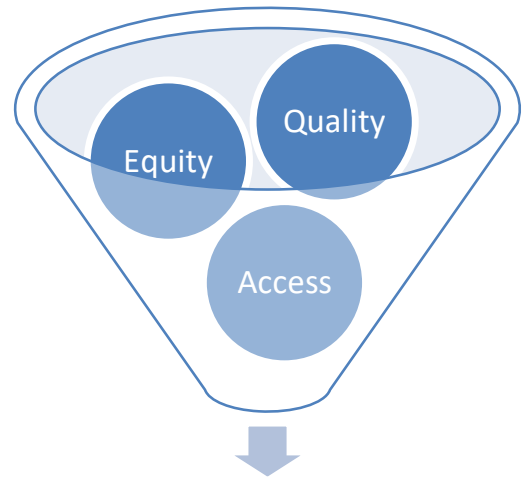

Social Justice

Figure1: The nexus of access, equity and quality as an epitome of social justice

Scott (2020) avers that fair access to higher education should be carefully considered because it reflects the digital poverty as a great show of unequal student access and engagement to online learning during the pandemic. The learning gap between students from varying social backgrounds climaxes the urgency of redressing pertinent social disparities and the need to level the plane for equitable access to education. Access and equity can arguably be deemed the two sides of the same coin, particularly in realising 
the availability of distance education for all. Section 9 and section 29(2a) of the constitution of South Africa (South Africa 1996) assert the need for effective access to education with consideration of equity and further assures the promotion and achievement of equality. Higher education institutions (HEIs) are public institutions and enterprises; thus they are required to uphold basic values such as social justice, respect and equity primers ease of access (Dlodlo 2018). For the purpose of this study, it is important to understand these values through the attributes access and equity and the way in which they relate to social justice.

\section{Access}

Access refers to gaining entry to online tuition or admission to acquire education in this context. A report by Motala et al. (2007) painted a gloomy picture regarding access to education by those students from exclusive zones. Yet, 24 years on, it remains endemic, with the pandemic freshly drawing it to focus. Distance education has previously been deemed most accessible for those unable to access other HEI, but is lately equally difficult to access (Ntombela and Setlhodi 2018). Some of those who succeeded, struggle to access tuition online owing to their socio-economic conditions, causing them to struggle with connectivity (Dichaba and Setlhodi 2017). This makes the idea of distance education which can be accessed from anywhere online difficult (Unisa 2008). The hardships of learning while battling with connection further threatens the possibility of acquiring quality education to change livelihoods (Käpplinger and Lichte 2020). Perpetual hardships while a significant amount of the state expenditure goes to education for relief to those in need is unfair (Scott 2020) and a travesty of justice. It undermines the gains that birthed democracy (Tlale and Mahlo 2016) and achieved equity.

\section{Equity}

Equity identifies that some people are more disadvantaged than others and intends to recompense for these injustices and socio-economic difficulties to ensure that everyone can attain the same education in this context. Campbell and Storo (1996) enunciate that equity refers to the equal treatment of students after obtaining access. Students from underprivileged communities need more support of the necessary devises and sufficient internet access to partake equally in distance education, yet have less access compared to their affluent or privileged counterparts (Seale 2020), in that way creating a learning gap. Letseka, Letseka, and Pitsoe (2018) aver that provision of distance education in a socio-economically vast disparity undermines the right to access education and an opportunity for equity in distance education. "Distance learning and equitable education both began with an emphasis on access, on providing underserved students with an increased access to education" (Campbell and Storo 1996, 284) to achieve social justice. Both equity and access are principles of social justice alongside equality and participation (Williams 2013). When education is equally accessible, measuring quality is credible and ethical. 


\section{Methodology and Material}

This study largely used the literature review method, inclusive of document analysis and conceptual analysis of ancillary sources of data, encompassing reports, recently peer-reviewed journal articles, policies, reports, social media comments and other online sources (see Table 1). According to Mhlanga and Moloi (2020), such methodology can benefit qualitative studies, particularly in data collection related to current affairs, and in essence, for ethical reasons. Issues of online quality assurance in relation to access and equity in the era of the pandemic are developing, hence the need for sensible ethical consideration.

Table 1: Material used for the study

\begin{tabular}{|l|l|}
\hline Material & Quantity acquired \\
\hline Journal articles & 35 \\
\hline Policies and legislation & 8 \\
\hline Reports & 13 \\
\hline Webinars, TED talks and YouTube clips & 7 \\
\hline Blogs & 5 \\
\hline News articles, broadcast and academic talk shows & 25 \\
\hline $\begin{array}{l}\text { Unisa assessment reports compiled by the academic } \\
\text { quality assurance and enhancement unit }\end{array}$ & 80 \\
\hline $\begin{array}{l}\text { Social media platforms of a distance education institution } \\
\text { under study (the institution enjoys the highest media heats } \\
\text { "with more fans, more likes and more followers" and } \\
\text { responses on Facebook, Twitter, LinkedIn in South } \\
\text { Africa's higher education space) (Unisa 2021) }\end{array}$ & 3 \\
\hline
\end{tabular}

The data were readily available and form part of the outcomes of varied formal and informal processes, including reports, and therefore convey the truths as captured, particularly over the pandemic period. The data were deemed more than sufficient for analysis (O'Leary 2014). Müller (2021) advises using available data that the researcher cannot influence or control as in this context require the use of visual tools for analysis because they enable thematic configuration of data. This study used the MAXQDA visual tools to analyse process-generated data. MAXQDA is a registered trademark of VERBI Software that is used for analysing data (Gizzi and Rädiker 2021).

The aforementioned data set had varying content per page and paragraph. Only the content linked to equity, access and quality aligned with COVID-19 and the concepts attributes, was considered analytical units and thus deemed suitable material for analysis. The social media comments were cut and pasted according to the concepts (equity, access and quality) regarding the pandemic. The objectives of this study were to identify whether the current measures (following Covid-19 protocol) are accessible to all students at the right time, and to establish the link between equity and access in 
relation to quality. The relevant documents were arranged according to content related to equity and access to determine the way in which these influence quality.

The documents bearing relevant text were split into three groups labelled according to equity, access and quality, using the code memo function. This enabled a thorough analysis of equity, access and quality through cross tabulation from the system menu, thereby yielding different colour coding in each case (Müller 2021). This process yielded the following themes through the frequent analysis process of co-occurrence of codes to ensure trustworthiness (Gizzi and Harm 2021), which are represented by the concepts attributes informing the themes:

- Socio-economic inequalities - disadvantages, vulnerability, financial pressure, poverty, unfairness, unemployment, government support, justice, high costs, delays in support, frustrations, deprivation, participation.

- Online education as the now strategy - online teaching, learning, assessment, access, data, ICT devises, connectivity, inability to keep track.

- Quality provision - credibility of assessment, student support, policy compliance, meeting set standards, reviews, monitoring.

\section{Results and Discussions}

The analysis process yielded three main themes with the concepts attributes. These concepts attributes directly point to the issues informing the themes. The concepts form part of the MAXQDA word combinations and phrases applied with the analytical tools used, as already discussed. Casasempere and Vercher-Ferrándiz (2021) suggest that word combinations are efficient in exploring large literature and text information to build a conceptual framework and analytical themes.

\section{Socio-Economic Inequalities}

The socio-economic concepts attributes yielded through the analysis process revealed that students from deprived environments were the most vulnerable and disadvantaged by ERT owing to the Covid-19 protocols (Bates 2020; Bonal and González 2020; Käpplinger and Lichte 2020; LeGrange 2020). Students from these underprivileged backgrounds have a socio-economic standing which compromises their ability to measure well with those who can afford the necessary commodities, which results in their studies being largely disadvantaged (LeGrange 2020; The World Bank 2020). Paterson (2021) confirms that students who relied on the university resources and vulnerable institutions were disadvantaged, further making it difficult for such institutions and students to cope with the ERT process. This further exacerbates the situation of those already affected by inequitable provision (Scott 2020), including those who could not afford the migration to ERT and learning while awaiting support from their institutions. 
Access and support remain complicatedly dependent on external sources (Opoku 2020). This inadvertently increased the prevailing gap between the "have and have not" (Bonal and González 2020). Social media expressions verbalised frustrations from those students who were affected. A twitter comment said: "It's like we're punished for being poor." A Facebook comment with 23.7k Likes and 5698 comments stated: "It's aluta continua for the poor," which means struggles continue for poor people. Students benefitting from bursaries from the National Student Financial Aid Scheme in South Africa were mostly affected, forcing the government to reprioritise money in favour of the fund (Koornhof 2020). That students struggle to access timeous education and feel left out emphasise the continuous imbalance of access to learning and perpetual equity divide that vexes needy students.

Ashman (2015) argues that all students, irrespective of their backgrounds and locations, should have learning opportunities. The delays in delivery of learning resources and provision of data meant that needy students forfeited ERTs and were unable to access online material, particularly at the initial rollout of support (Hedding et al. 2020), further causing distress to those affected. Women were further disadvantaged because of their added responsibilities of taking care of their families (Käpplinger and Lichte 2020), resulting in the gender inequity unintentionally holding them back. If education is to be seen as an investment for a productive society (Green et al. 2021), adversities like these will perpetually render underprivileged societies unproductive. This portrays the hallmark of an unequal society and the dire urgency for education institutions, particularly ODeL, to streamline online education, which is accessible to all students. It is therefore essential to prioritise their needs to espouse justice and transact good to humanity.

\section{Online Education as the Now Strategy}

Covid-19 has exposed that leaders in HEIs need to realise that online education is the priority for now and has to be accessible for all students. Considering strategies to provide ICT devices and reliable connectivity is crucial. Letseka, Letseka, and Pitsoe (2018) suggest that ODeL institutions in their nature offer tuition online and should therefore make it accessible for all students. Making any other matters take precedence over online education during Covid-19 suggests that institutions have not grasped the reality of the current transformation in education. Koornhof (2020) submits that some universities have instead prioritised the pandemic itself, followed by financial stability, thereby making their main purpose secondary. Such inexorability is a situation of missed opportunity to tackle inequality and misfortune of access to online learning. Sokhulu (2020) opines that technology that enables distance learning is a formidable asset, the greatest source of advancement, and an efficient tool to redress the equity gap.

The intention to bring equity and close the gap through education is therefore thwarted when some students are unable to access education (Green et al. 2021). Dichaba and Setlhodi (2017) found that affordance was the main challenge for needy students who struggled accessing new technologies and data, which maintained the status quo for 
those from deprived environments. It further perpetuates inequalities because students who do not have financial means continue to be disadvantaged and distressed. Ng'ambi and Bozalek $(2013,8)$ suggest that knowing the latest technologies within HEIs marks the critical realisation for institutional leaders to prioritise technology acceptance of new technologies. Even though there are efforts to intensify online access to education through partnerships with mobile companies and the use of various Fourth Industrial Revolution (4IR) tools, those who should be benefitting more seem to be the most disadvantaged (Ng'ambi and Bozalek 2013,9), given challenges such as continued connectivity and poor bandwidth, availability of data, and suitable technological devices. Dwolatzky and Harris (2020) reported that connectivity data costs were a problem to even those with internet, as well as the lack of suitable devises and digital acumen during the lockdown, which resulted in a large learning disparity. Scott (2020) maintains that digital illiteracy itself signifies incongruence and raises a stark gap between those students who can afford it and those who cannot. Setbacks like these can unintentionally have a huge impact on the quality of education and academic success.

\section{Quality Provision}

According to Gustafsson and Deliwe (2020), trends in South Africa reveal that the quality of education has been adversely affected by the pandemic, with some students having missed out on online learning opportunities owing to other socio-economic issues. Even though some of these students may have progressed to the next level of their education, the knowledge gap caused by missing out on their learning raises a concern on the quality of their assessment results. Baijnath (2018) suggests that HEIs in South Africa have to provide quality education to ensure that students do not lag behind. The need is therefore to prioritise support for students to ascertain that issues of offering quality higher education, particularly in distance education spaces, are dealt with to adequately mitigate problems that may erupt owing to issues arising from the pandemic (Madiope and Mendy 2021). Provision of support entails authentic steps taken to strengthen remote learning to maintain credible offerings (Dipa 2020). The University of South Africa (Unisa) has a platform called myUnisa for students and lecturers to engage in discussions and intensified the use of the platform to ensure that students were adequately supported and prepared for online assessments (Unisa 2020). Recorded lessons through the use of Tippy Tubes, within the college of education, were used and students could freely access the learning material to learn and prepare for their online assessment, which was deemed successful and credible (Mahope 2020).

However, students who could not access online material or struggled with weak connections were disadvantaged as they could not prepare adequately or complete and submit their assessments online (AQAE Reports 2020). This meant that students had to either apply for supplementary assessment or defer their assessment to the following semester (Shuma 2020), further disadvantaging those who require help most. Stringent quality measures were followed to ascertain quality assessment, even though there were media concerns of possible irregularities. However, the examination format adopted ensured that quality assessment was maintained through plagiarism tools and virtual 
proctoring (Mahope 2020), with staff working from home and beyond normal working hours to ensure credibility of the online assessments (Shuma 2020). Comments from various social media platforms and the media confirmed that it was not possible for students to engage in irregularities even though they were assessed remotely (Fengu 2020). A student remarked: "With all the anxiety and the stress ... with Covid-19 I'm . . . best is good enough" (Shuma 2020). Another student said: "It's literally setting us up for failure" (Govender 2020). By failing to advance social justice and to redress equity issues (Letseka, Letseka, and Pitsoe 2018,127), social justice cannot be advanced.

\section{Conclusion}

Perpetual hardships while a significant amount of the state expenditure goes to education for relief to those in need is unfair (Scott 2020) and a travesty of justice. The objectives of this study were to identify whether the current measures (following Covid19 protocol) are accessible to all students at the right time, and to establish the link between equity and access in relation to quality. The interplay of access, equity and quality brought about by the implementation of the ERT in response to the pandemic protocol, resuscitated issues of social justice in distance education overall. Access to ERT during the pandemic is problematic for students from disadvantaged backgrounds, highlighting equity concerns and exposing the limitations these may bring in assuring quality education. The conceptual framework was presented to define relevant variables and their relationships in relation to ERT. A qualitative methodology was employed, using the MAXQDA visual analysis tool, to analyse the literature reviewed in this study. The concepts of access, equity and quality raised social justice issues and possible impediments in attaining quality education, thus raising a red flag to the provision of quality education for all.

The limitation of this study is that data of other researchers were used and may not have adequately covered the concepts of access, equity and quality. Future research could probe these concepts in relation to inclusion of learners from diverse backgrounds. The paper recommends that distance education require leaders to prioritise online education and what is required to make it accessible, related online learning material that is accessible for all, tackle social justice issues and possible impediments towards attaining quality education, and the support for needy students.

\section{References}

AQAE (Academic Quality Assurance and Enhancement) Reports - Examination Module Reports. 2020. "May/June Online Assessment: Checking and Fixing Online Exams' Issues (Complaints) on the Same Day." Academic Quality Assurance and Enhancement Directorate: University of South Africa. 25 May 2020 - 6 July 2020. 
Adom, D., E. K. Hussein, and J. A. Agyem. 2018. "Theoretical and Conceptual Framework: Mandatory Ingredients of a Quality Research.” International Journal of Scientific Research 7 (1): 438-41.

Ashman, A. 2015. Education for Inclusion and Diversity. Melbourne: Victoria: Pearson.

Bonal, X., and S. González. 2020. "The Impact of Lockdown on the Learning Gap: Family and School Divisions in Times of Crisis." International Review of Education 66: 635-55 https://doi.org/10.1007/s11159-020-09860-z.

Baijnath, N. 2018. "Learning for Development in the Context of South Africa: Considerations for Open Education Resources in Improving Higher Education Outcomes." Journal of Learning for Development 5 (2): 87-100.

Campbell, P., and J. Storo. 1996. "Reducing the Distance: Equity Issues in Distance Learning in Public Education.” Journal of Science Education and Technology 5 no.4 p284-295. https://doi.org/10.1007/BF01677125.

Casasempere-Satorres, M., and M. Vercher-Ferrándiz. 2021. "Using MAXQDA for Bibliographic Documentary Analysis: Combining Automatic and Manual Procedures within a Literature Review. In The Practice of Qualitative Data Analysis Research: Examples Using MAXQDA, edited by M. C. Gizzi and S. Rädiker, 149-161. Berlin: MAXQDA Press.

Cloete, N. 2011. "New South African Realities.” In Transformation in Higher Education: Global Pressures and Local Realities in South Africa, edited by N. Cloete, P. Maassen, R. Fehnel, T. Moja, T. Gibbon and H. Perold, 269-288. 2nd ed. Dordrecht: Kluwer Academic. https://doi.org/10.1007/1-4020-4006-7_22.

Council on Higher Education. 2015. "Transformation in Higher Education.” Paper presented at the second National Higher Education Summit, 15-17 October 2015.

Dichaba, M., and I. Setlhodi. 2017. “Understanding Students' Affordances of New Media Technologies in Open Distance Learning at Unisa." Paper presented at the South Africa International Conference on Educational Technologies, 24-26 April 2017, Pretoria, Manhattan Hotel.

Dipa, K. 2020. “Covid-19 Presents Curricula Crunch for SA's Universities.” Saturday Star, 27 April 2020. https://www.iol.co.za/saturday-star/news/covid-19-presents-curriculacrunch-for-sas-universities- 47191206.

Dlodlo, A. 2018. "Building a Value-Driven Public Service through Ethical Leadership for Service Delivery." Speech presented at the launch of the Constitutional Values and Principles (CVPs), 20 September 2018, Z. K. Matthews Hall, University of South Africa. 
Dwolatzky, B., and M. Harris. 2020. "SA Education: A National Reset is Needed and Mass Internet Access is the only Way Forward.” The Daily Maverick, 2 July 2020. https://www.dailymaverick.co.za/article/2020-07-02-sa-education-a-national-reset-isneeded-and-mass-internet-access-is-the-only-way-forward/.

Fengu, M. 2020. “Unisa Students Unhappy with Online Exams.” City Press, 8 May 2020. https:/www.news24.com/citypress/news/unisa-students-unhappy-with-online-exams20200511.

Gizzi, M. C., and A. Harm. 2021. "Using MAXQDA from Literature Review to Analyzing Coded Data: Following a Systematic Process in Student Research.” In The Practice of Qualitative Data Analysis Research: Examples Using MAXQDA, edited by M. C. Gizzi and S. Rädiker. Berlin: MAXQDA Press.

Gizzi, M. C. and S. Rädiker. 2021. The Practice of Qualitative Data Analysis Research: Examples Using MAXQDA. Berlin: MAXQDA Press.

Govender, P. 2020. “'It's Literally Setting Us up for Failure': Students' Fury at Online Exam Dates." Sunday Times, 8 October 2020. https://www.timeslive.co.za/sunday-timesdaily/news/2020-10-08-its-literally-setting-us-up-for-failure-students-fury-at-unisa-examdates/.

Green, C., L. Mynhier, J. Banfill, P. Edwards, J. Kim, and R. Desjardins. 2021. "Preparing Education for the Crises of Tomorrow: A Framework for Adaptability." International Review of Education 66: 857-79. https://doi.org/10.1007/s11159-020-09878-3.

Gustafsson, M., and C. N. Deliwe. 2020. "How is the COVID-19 Pandemic Affecting Educational Quality in South Africa? Evidence to Date and Future Risks." https://ideas.repec.org/p/sza/wpaper/wpapers358.html.

Hedding, D. W., M. Greve, G. D. Breetzke, W. Nel, and B. Jansen van Vuuren. 2020. "COVID-19 and the Academe in South Africa: Not Business as Usual." South African Journal of Science 116 (7/8). https://doi.org/10.17159/sajs.2020/8298.

Käpplinger, B., and N. Lichte. 2020. “The Lockdown of Physical Co-Operation Touches the Heart of Adult Education: A Delphi Study on Immediate and Expected Effects of COVID-19." International Review of Education 66: 777-95. https://doi.org/10.1007/s11159-020-09871-w.

Koornhof, C. 2020. "OPINION Covid-19: The Impact on Universities and how their Business Models Need to Flexible.” News24, 9 October 2020.

https://www.news24.com/news24/columnists/guestcolumn/opinion-covid-19-the-impacton-universities-and-how-their-business-models-need-to-flexible-20201009.

LeGrange, L. 2020. "Covid-19 Pandemic and the Prospects of Education in South Africa. Prospects.” UNESCO IBE. https://doi.org/10.1007/s11125-020-09514-w. 
Letseka, M., M. M. Letseka, and V. Pitsoe. 2018. "The Challenge of E-Learning in South Africa." https://doi.org/10.5772/intechopen.74843.

Lucander, H., and C. Christersson. 2020. "Engagement for Quality Development in Higher Education: A Process for Quality Assurance of Assessment." Quality in Higher Education 26 (2): 135-55. https://10.1080/13538322.2020.1761008.

Madiope, M., and J. Mendy. 2021. "Analysis of Current Trends in Distance Education during COVID-19: A South African Higher Education Context." Online Journal of Distance Education and E-Learning 9 (1).

Mahope, R. 2020. “No Online Exam Cheating, says Unisa.” Pretoria Rekord, 20 May 2020. https://rekord.co.za/339073/no-online-exam-cheating-says-unisa/.

Mhlanga, D., and T. Moloi. 2020. "COVID-19 and the Digital Transformation of Education: What are We Learning on 4IR in South Africa?" Education Sciences 10: 180. https://doi.org/10.3390/educsci10070180.

Mncube, V. S., and N. Madikizela-Madiya. 2013. "South African Educational Reform Curriculum, Governance and Teacher Education." In Education in Southern Africa, edited by C. Harber. London: Bloomsbury. https://doi.org/10.5040/9781472544476.ch-007.

Motala, S., V. Dieltiens, N. Carrim, P. Kgobe, G. Moyo, and S. Rembe. 2007. Educational Access in South Africa: Country Analytic Report. Brighton: Consortium for Research on Educational Access, Transitions and Equity.

Müller, Andreas. 2021. “An Example with Historical Legal Documents.” In The Practice of Qualitative Data Analysis Research: Examples Using MAXQDA, edited by M. C. Gizzi and S. Rädiker. Berlin: MAXQDA Press.

Ng'ambi, D., and V. Bozalek. 2013. "Leveraging Informal Leadership in Higher Education Institutions: A Case of Diffusion of Emerging Technologies in a Southern Context." British Journal of Educational Technology 44 (6): 940-50. https://doi.org/10.1111/bjet.12108.

Ntombela, S., and I. Setlhodi. 2021. "Transformation and Social Justice in South African Higher Education: An Unequal Turf." In Information Resources Management Association (IRMA). Research Anthology on Instilling Social Justice in the Classroom 1248-1262. https://doi.org/10.4018/978-1-7998-7706-6.

Opoku, M. P. 2020. "Inclusive Education without Resources: A Policy Approach for SubSaharan Africa." In Developing Teaching and Learning in Africa: Decolonising Perspectives, edited by V. Msila, 59-74. Stellenbosch: African Sun Media. https://doi.org/10.18820/9781928480716/04.

O’Leary, Z. 2014. The Essential Guide to Doing your Research Project. 2nd ed. Thousand Oaks: Sage. 
Paterson, M. 2021. “COVID-19 and Higher Education: Damage Done, Lessons Learnt.” University World News: Africa Edition. 12 April 2021.

https://www.universityworldnews.com/post.php?story=20210211103422612.

Scott, P. 2020. The Impact of Covid-19 on Fair Access to Higher Education. Edinburgh: Commissioner for Fair Access..

Seale, C. 2020. "Distance Learning during the Coronavirus Pandemic: Equity and Access Questions for School Leaders.” Forbes, 17 March 2020.

https://www.forbes.com/sites/colinseale/2020/03/17/distance-learning-during-thecoronavirus-pandemic-equity-and-access-questions-for-schoolleaders/?sh=34d015211d4d.

Shuma, P. 2020. "UNISA Conducts Online Exams for First Time ever, Some Students Feel Overwhelmed." South African Broadcasting Cooperation, 29 May 2020. https://www.sabcnews.com/sabcnews/unisa-conducts-online-exams-for-first-time-eversome-students-feel-overwhelmed.

Sokhulu, L. H. 2020. "Students' Experiences of Using Digital Technologies to Address their Personal Research Needs during the COVID-19 Lockdown." African Identities. https://doi.org/10.1080/14725843.2020.1801384.

South Africa. 1996. The Constitution of South Africa, 1996 (Act No. 108 of 1996). Pretoria: Government Printers.

The World Bank. 2020. Guidance Note: Remote Learning and COVID-19. Washington: The World Bank.

Tlale D., and D. Mahlo. 2016. "Inclusive Education and Ubuntu in Open and Distance Education.” In Open Distance Learning (ODL) through the Philosophy of Ubuntu, edited by M. Letseka, 163-174. New York: Nova.

Unisa (University of South Africa). 2008. Open Distance Learning Policy. Pretoria: Unisa Press.

Unisa (University of South Africa). (2020). "Connect Online." https://www.unisa.ac.za/sites/myunisa/default/Study-@-Unisa/Prepare-for-studysuccess/Connect-online.

Unisa (University of South Africa). 2021. “Unisa Media Strategy.” Pretoria: Unisa.

Williams, J. 2013. "Equity in Distance Education.” In Global Challenges and Perspectives in Blended and Distance Education, edited by J. Willems, 17-34. IGI Global. https://doi.org/10.4018/978-1-4666-3978-2.ch002. 